\title{
Associations between HVEM/LIGHT/BTLA/CD160 polymorphisms and the occurrence of antibody-mediate rejection in renal transplant recipients
}

\author{
Zijie Wang $^{1, *}$, Ke Wang ${ }^{1, *}$, Haiwei Yang ${ }^{1, *}$, Zhijian Han ${ }^{1}$, Jun Tao ${ }^{1}$, Hao Chen ${ }^{1}$, Yuqiu \\ $\mathbf{G e}^{2}$, Miao Guo ${ }^{3}$, Chuanjian Suo ${ }^{1}$, Ji-Fu Wei ${ }^{3}$, Ruoyun $\operatorname{Tan}^{1}$ and Min Gu${ }^{1}$ \\ ${ }^{1}$ Department of Urology, The First Affiliated Hospital With Nanjing Medical University, Nanjing, China \\ ${ }^{2}$ School of Public Health, Nanjing Medical University, Nanjing, China \\ ${ }^{3}$ Research Division of Clinical Pharmacology, The First Affiliated Hospital With Nanjing Medical University, Nanjing, China \\ *These authors have contributed equally to this work \\ Correspondence to: Min Gu, email: lancetgu@aliyun.com \\ Ruoyun Tan, email: tanruoyun112@vip.sina.com
}

Keywords: kidney transplantation, antibody-mediated rejection, costimulatory signals, single-nucleotide polymorphisms next generation sequencing

Received: June 08, $2017 \quad$ Accepted: August 19, $2017 \quad$ Published: October 19, 2017

Copyright: Wang et al. This is an open-access article distributed under the terms of the Creative Commons Attribution License 3.0 ( CC BY 3.0), which permits unrestricted use, distribution, and reproduction in any medium, provided the original author and source are credited.

\section{ABSTRACT}

Antibody-mediated rejection (ABMR) is a serious complications that can occur following renal transplantation. The production of donor-specific antibodies by the humoral immune response can trigger costimulatory signals, which are crucial in activating immune cells, and therefore, playing a potential role in ABMR. To investigate the role of HVEM/LIGHT/BTLA/CD160 polymorphisms in ABMR, we retrospectively analyzed 200 renal transplant recipients. We adopted next-generation sequencing (NGS) to identify HVEM/LIGHT/BTLA/CD160 single-nucleotide polymorphisms (SNPs) in the genotypes of these patients. We divided the patients into two groups: those with ABMR and those who were stable. We adopted multiple models and performed regression analysis after adjusting for multiple confounding variables, to determine the correlation between the SNPs and ABMR. We obtained 41 high-quality SNPs readouts. However, we did not observe any significant association between these polymorphisms and the pathogenesis of ABMR in any of the models. Nevertheless, since there is evidence suggesting the involvement of costimulatory signals in graft rejection, further research should be conducted to better understand how genetic polymorphisms may be involved in ABMR.

\section{INTRODUCTION}

Kidney transplantation is an optimal choice for patients with end-stage renal disease. It is considered superior to dialysis, due to the reduced complications, lower mortality rates and improvement to patient quality of life [1]. However, antibody-mediated rejection (ABMR), also termed as humoral rejection, poses a substantial threat to post-transplant patients and inevitably leads to allograft loss [2]. The precise pathogenesis of ABMR remains unclear. Generally, ABMR is closely associated with antibodies ligating to donor antigens, which mediate allograft damage via activation of the complement system or cytotoxic cells $[3,4]$. These antibodies are directed against human leukocyte antigens (HLAs) and major histocompatibility complex (MHC) class I and II antigens, termed as donor-specific antibodies (DSAs) [5]. Meanwhile, they can also be directed against other stimulators, such as minor histocompatibility antigens, $\mathrm{ABO}$ group antigens and endothelia cell antigens [6, 
7]. Although ABMR occurs in less than $10 \%$ of renal transplant recipients, $30 \%$ of them ultimately suffer from graft loss [3]. As a result, ABMR impacts the long-term graft survival in kidney transplantation and is one of the most challenging clinical events following renal transplant [8].

Activation of both $\mathrm{T}$ and $\mathrm{B}$ cells after transplantation is a tightly regulated process consisting of multiple distinct but interrelated signals [9]. Secondary signals, also named costimulatory signals, play an important role in activation and inhibition of immune cells. Recently, much attention has been placed on HVEM (herpes virus entry mediator) and LIGHT (homologous to lymphotoxin, which exhibit inducible expression and compete with HSV glycoprotein D for binding to HVEM, a receptor expressed on T lymphocytes), BTLA (B and T lymphocyte attenuator) and CD160 costimulatory pathways. HVEM and LIGHT belong to the TNFR superfamily, while BTLA and CD160 are members of the Ig superfamily. The functions and structures of these costimulatory molecules can be divided into positive and negative costimulatory pathways [10]. The binding of HVEM on T cells to membrane-bound LIGHT delivers positive signals through HVEM that promotes T-cell survival, while the conjugation of HVEM to CD160/BTLA on T cells delivers a coinhibitory signal that deactivates T-cells [1114]. There is substantial evidence that suggests disorder of the HVEM/LIGHT/BTLA/CD160 signaling system is essential in the development of autoimmune diseases and allograft rejection $[15,16]$. Costimulatory signals are widely investigated in $\mathrm{T}$ cell mediated immunity. However, regarding humoral immunity, the role of the HVEM/LIGHT/BTLA/CD160 costimulatory system in $B$ cell activation and allograft transplantation remains unclear. Studies suggest that HVEM is expressed at high levels in all peripheral blood B cells, while at low levels in germinal center (GC) B lymphocytes, which may be activated since $\mathrm{GC}$ is where dendritic cells (DC), T cells and $\mathrm{B}$ cells interact [17]. It is postulated that LIGHT expression on DC and T cells causes HVEM engagement on naïve B cells, which costimulates B cell proliferation and Ig secretion, as a result, enhancing humoral immune responses [13]. It has also been suggested that de novo DSAs is needed in the cognate interaction between CD4 ${ }^{+}$ $\mathrm{T}$ follicular helper cells ( $\mathrm{Tfh}$ ), which are primed by donor alloantigens and presented as host antigen presenting cells and $\mathrm{B}$ lymphocytes that recognize soluble and membranebound alloantigens. This suggests the possibility that HVEM/LIGHT/BTLA/CD160 participates in the modulation of DSAs and humoral immune response [1820].

Until now, the association between HVEM/ $L I G H T / B T L A / C D 160$ gene polymorphisms and ABMR in renal transplant recipients has remained unexplored. Here, we evaluated the association between a total 41 single nucleotide polymorphisms (SNPs) of HVEM/
LIGHT/BTLA/CD160 genes and occurrence of ABMR and investigated its role in the formation of DSAs and pathogenesis of $A B M R$ in renal transplantation recipients.

\section{RESULTS}

\section{Demographic and clinical characteristics}

The demographic characteristics of the renal transplant recipients are shown in Table 1. This study included 200 patients from the Chinese Han population: 69 renal transplant recipients had ABMR (40 men and 29 women), while 131 were considered stable ( 82 men and 49 women). The immunosuppressive protocols administered in stable and ABMR groups are also presented. Among patients in ABMR groups, we further collected ABMRrelated clinical information, such as $\mathrm{C} 4 \mathrm{~d}$ scoring, histological classifications and the level of serum DSAs, and reported them in Table 1. We did not observe any significant differences $(P>0.05)$ in age, sex, donor type and immunosuppressive protocol between the stable and ABMR group.

\section{Association of $H V E M / L I G H T / B T L A / C D 160$ SNPs with ABMR}

Previous investigations into HVEM/LIGHT/BTLA SNPs have been limited to rs2234163, rs2234165 and rs2234167 for HVEM SNPs, rs344560 and rs2291667 for LIGHT SNPs, and rs9288952, rs2171513 and rs76844316 for BTLA SNPs. However, in our study, we screened the genetic distribution of 41 HVEM/LIGHT/ $B T L A / C D 160$ SNPs, which we show in Table 2. All genotype frequencies in the control group conformed to the Hardy-Weinberg equilibrium (HWE) $(P>0.05$; Table $2)$. In logistic regression analysis and corrected for age, sex, and immunosuppressive protocols (Table 3 ), we did not find any significant associations $(P<0.05)$ between the occurrence of ABMR and polymorphisms in any of the 41 $H V E M / L I G H T / B T L A / C D 160$ SNPs among the different models.

\section{DISCUSSION}

To the best of our knowledge, this is the first study that deploys next-generation sequencing (NGS) technology to investigate the association between HVEM/ LIGHT/BLTA/CD160 SNPs and ABMR in renal transplant recipients. We screened a total 41 SNPs, previously unexplored in the context of ABMR, and show that none of the polymorphisms were significantly associated with the onset of ABMR in renal transplant recipients.

HVEM belongs to the TNF receptor superfamily and acts as a shared ligand for the costimulatory and coinhibitory receptor [13]. Human HVEM is a type 1 transmembrane glycoprotein with four pseudo repeats of the cysteine-rich 
Table 1: Basic characteristics of patients included in our study

\begin{tabular}{|c|c|c|c|}
\hline Characteristics & Stable group & ABMR group & $P$ value \\
\hline Case number & 131 & 69 & NS \\
\hline Age (years; mean \pm SD) & $38.56 \pm 1.40$ & $38.92 \pm 1.02$ & NS \\
\hline Male (\%) & 62.60 & 57.97 & NS \\
\hline PRA (\%) & 0 & 0 & NS \\
\hline Donor type & & & NS \\
\hline Living-related & 16 & 7 & \\
\hline DCD & 115 & 62 & \\
\hline $\begin{array}{l}\text { Immunosuppressive } \\
\text { protocol }\end{array}$ & & & NS \\
\hline Pred + MMF + CsA & 62 & 26 & \\
\hline Pred + MMF + TAC & 60 & 35 & \\
\hline Pred + MMF + CsA + SIR & 5 & 6 & \\
\hline Pred + MMF + TAC + SIR & 4 & 2 & \\
\hline \multicolumn{4}{|l|}{ Type of $A B M R^{*}$} \\
\hline Acute ABMR & - & 23 & \\
\hline Chronic active ABMR & - & 46 & \\
\hline \multicolumn{4}{|l|}{$\begin{array}{l}\text { Grade of morphologic tissue } \\
\text { injury }^{*}\end{array}$} \\
\hline Grade I & - & 25 & \\
\hline Grade II & - & 34 & \\
\hline Grade III & - & 10 & \\
\hline \multicolumn{4}{|l|}{ C4d Scroing by IF } \\
\hline C4d1 & - & 5 & \\
\hline $\mathrm{C} 4 \mathrm{~d} 2$ & - & 17 & \\
\hline $\mathrm{C} 4 \mathrm{~d} 3$ & - & 47 & \\
\hline \multicolumn{4}{|l|}{$\begin{array}{l}\text { Criculating DSAs (MFI, } \\
\text { mean } \pm S D)\end{array}$} \\
\hline Class I & - & $1368.12 \pm 550.96$ & \\
\hline Class II & - & $1191.23 \pm 655.88$ & \\
\hline
\end{tabular}

Abbreviations: ABMR, antibody-mediated rejection; NS, not significant; SD, standard deviation; PRA, panel reactive antibody; Pred, prednisone; MMF, Mycophenolate Mofetil; CsA, Cyclosporin A; TAC, tacrolimus; SIR, sirolimus; IF, immunofluorescence; DSA, donor-specific antibody.

${ }^{*}$ The classification of ABMR are in accordance with Banff 2007 criteria.

domain (CRD) in its extracellular domain. It is expressed widely on $\mathrm{T}$ cells, $\mathrm{B}$ cells and other hematopoietic (DC, Tregs, monocytes, neutrophils, and NK cells) and nonhematopoietic cells (parenchymal cells) [13]. HVEM serves a central role in the HVEM/LIGHT/BTLA/CD160 costimulatory pathway, directing both positive (LIGHT) and negative (BTLA/CD160) costimulatory signals depending its receptor [21]. Rs2234163, rs2234165 and rs2234167, which are included in our study, have been researched in association with HVEM polymorphism and sporadic breast cancer [22]. In this instance, Dalin Li et al. reported that rs2234167, which is in the exon of the HVEM gene, is significantly associated with increased breast cancer risk, and presumed to influence the binding affinity between HVEM and BTLA/LIGHT/CD160 [22]. In our study, however, we 
Table 2: Genetic distributions of $H V E M / L I G H T / B T L A / C D 160$ polymorphisms between the ABMR and stable group

\begin{tabular}{|c|c|c|c|c|c|c|}
\hline \multirow{2}{*}{ Genotype } & \multirow{2}{*}{ Chromosome } & \multirow{2}{*}{ Position } & \multirow{2}{*}{$\begin{array}{l}\text { Stable group } \\
\quad(\mathbf{n}=131)\end{array}$} & \multirow{2}{*}{$\begin{array}{c}\text { ABMR group } \\
(n=69)\end{array}$} & \multicolumn{2}{|c|}{ HWE for the stable group } \\
\hline & & & & & $\mathrm{X} 2$ & $P$ value \\
\hline \multicolumn{7}{|l|}{ HVEM } \\
\hline rs4870 & Chr1 & 2488153 & & & 0.74 & 0.69 \\
\hline $\mathrm{AA}$ & & & 38 & 24 & & \\
\hline $\mathrm{AG}$ & & & 70 & 34 & & \\
\hline GG & & & 23 & 11 & & \\
\hline rs2234158 & Chr1 & 2489200 & & & $<0.01$ & 0.99 \\
\hline $\mathrm{CC}$ & & & 103 & 69 & & \\
\hline $\mathrm{CT}$ & & & 1 & 0 & & \\
\hline rs376994775 & Chr1 & 2489746 & & & $<0.01$ & 0.99 \\
\hline $\mathrm{CC}$ & & & 130 & 69 & & \\
\hline $\mathrm{CT}$ & & & 1 & 0 & & \\
\hline rs754021885 & Chr1 & 2489961 & & & $<0.01$ & 0.99 \\
\hline $\mathrm{CC}$ & & & 130 & 68 & & \\
\hline CT & & & 1 & 1 & & \\
\hline rs572222644 & Chr1 & 2491163 & & & $<0.01$ & 0.99 \\
\hline $\mathrm{CC}$ & & & 131 & 68 & & \\
\hline $\mathrm{CT}$ & & & 0 & 1 & & \\
\hline rs2234161 & Chr1 & 2491205 & & & $<0.01$ & 0.99 \\
\hline $\mathrm{CC}$ & & & 36 & 20 & & \\
\hline $\mathrm{CT}$ & & & 65 & 35 & & \\
\hline TT & & & 30 & 14 & & \\
\hline rs2234162 & Chr1 & 2491305 & & & $<0.01$ & 0.99 \\
\hline $\mathrm{CC}$ & & & 130 & 69 & & \\
\hline $\mathrm{CT}$ & & & 1 & 0 & & \\
\hline rs 2234163 & Chr1 & 2491306 & & & 0.23 & 0.89 \\
\hline GG & & & 123 & 64 & & \\
\hline GA & & & 8 & 5 & & \\
\hline rs 2234165 & Chr1 & 2492276 & & & 0.39 & 0.82 \\
\hline GG & & & 120 & 63 & & \\
\hline GA & & & 11 & 6 & & \\
\hline rs575127151 & Chr1 & 2492935 & & & $<0.01$ & 0.99 \\
\hline GG & & & 131 & 68 & & \\
\hline GA & & & 0 & 1 & & \\
\hline rs375010878 & Chr1 & 2493087 & & & $<0.01$ & 0.99 \\
\hline $\mathrm{CC}$ & & & 130 & 68 & & \\
\hline $\mathrm{CT}$ & & & 1 & 1 & & \\
\hline & & & & & & (Continued) \\
\hline
\end{tabular}




\begin{tabular}{|c|c|c|c|c|c|c|}
\hline \multirow{2}{*}{ Genotype } & \multirow{2}{*}{ Chromosome } & \multirow{2}{*}{ Position } & \multirow{2}{*}{$\begin{array}{l}\text { Stable group } \\
\quad(n=131)\end{array}$} & \multirow{2}{*}{$\begin{array}{c}\text { ABMR group } \\
(n=69)\end{array}$} & \multicolumn{2}{|c|}{ HWE for the stable group } \\
\hline & & & & & $\mathrm{X} 2$ & $P$ value \\
\hline rs 2234167 & Chr1 & 2494330 & & & 0.16 & 0.92 \\
\hline GG & & & 123 & 66 & & \\
\hline GA & & & 8 & 3 & & \\
\hline rs8725 & Chr1 & 2494785 & & & 0.01 & 0.99 \\
\hline GG & & & 37 & 19 & & \\
\hline GA & & & 64 & 35 & & \\
\hline AA & & & 30 & 15 & & \\
\hline rs376495994 & Chr1 & 2496492 & & & $<0.01$ & 0.99 \\
\hline GG & & & 131 & 68 & & \\
\hline GA & & & 0 & 1 & & \\
\hline rs 186536172 & Chr1 & 2496521 & & & $<0.01$ & 0.99 \\
\hline $\mathrm{CC}$ & & & 130 & 68 & & \\
\hline CT & & & 1 & 1 & & \\
\hline rs7544646 & Chr1 & 2496649 & & & 0.38 & 0.83 \\
\hline $\mathrm{CC}$ & & & 47 & 19 & & \\
\hline $\mathrm{CG}$ & & & 59 & 35 & & \\
\hline GG & & & 25 & 15 & & \\
\hline rs 7515633 & Chr1 & 2496653 & & & 0.18 & 0.91 \\
\hline AA & & & 43 & 19 & & \\
\hline $\mathrm{AG}$ & & & 61 & 35 & & \\
\hline GG & & & 27 & 15 & & \\
\hline \multicolumn{7}{|l|}{ LIGHT } \\
\hline rs344560 & Chr19 & 6665020 & & & 0.55 & 0.76 \\
\hline $\mathrm{TC}$ & & & 13 & 7 & & \\
\hline $\mathrm{CC}$ & & & 118 & 62 & & \\
\hline rs772372888 & Chr19 & 6665098 & & & $<0.01$ & 0.99 \\
\hline $\mathrm{CC}$ & & & 130 & 69 & & \\
\hline $\mathrm{CT}$ & & & 1 & 0 & & \\
\hline rs61761328 & Chr19 & 6665099 & & & 0.02 & 0.99 \\
\hline GG & & & 127 & 69 & & \\
\hline GA & & & 4 & 0 & & \\
\hline rs183886666 & Chr19 & 6665336 & & & $<0.01$ & 0.99 \\
\hline GG & & & 131 & 68 & & \\
\hline GA & & & 0 & 1 & & \\
\hline
\end{tabular}

(Continued) 


\begin{tabular}{|c|c|c|c|c|c|c|}
\hline \multirow{2}{*}{ Genotype } & \multirow{2}{*}{ Chromosome } & \multirow{2}{*}{ Position } & \multirow{2}{*}{$\begin{array}{l}\text { Stable group } \\
\quad(n=131)\end{array}$} & \multirow{2}{*}{$\begin{array}{c}\text { ABMR group } \\
\quad(n=69)\end{array}$} & \multicolumn{2}{|c|}{ HWE for the stable group } \\
\hline & & & & & $\mathrm{X} 2$ & $P$ value \\
\hline rs8101047 & Chr19 & 6665481 & & & 1.24 & 0.54 \\
\hline AA & & & 4 & 0 & & \\
\hline$A G$ & & & 38 & 25 & & \\
\hline GG & & & 89 & 44 & & \\
\hline rs542346038 & Chr19 & 6667076 & & & $<0.01$ & 0.99 \\
\hline GG & & & 130 & 69 & & \\
\hline GA & & & 1 & 0 & & \\
\hline rs2291668 & Chr19 & 6669934 & & & 4.37 & 0.11 \\
\hline GG & & & 63 & 26 & & \\
\hline GA & & & 57 & 38 & & \\
\hline AA & & & 11 & 5 & & \\
\hline rs2291667 & Chr19 & 6669986 & & & 0.05 & 0.98 \\
\hline GG & & & 128 & 66 & & \\
\hline GA & & & 3 & 3 & & \\
\hline rs 748673655 & Chr19 & 6669992 & & & $<0.01$ & 0.99 \\
\hline $\mathrm{CC}$ & & & 130 & 69 & & \\
\hline $\mathrm{CT}$ & & & 1 & 0 & & \\
\hline rs344558 & Chr19 & 6670253 & & & 0.04 & 0.98 \\
\hline AA & & & 114 & 56 & & \\
\hline $\mathrm{AC}$ & & & 17 & 12 & & \\
\hline $\mathrm{CC}$ & & & 0 & 1 & & \\
\hline rs563748272 & Chr19 & 6677752 & & & $<0.01$ & 0.99 \\
\hline GG & & & 130 & 69 & & \\
\hline GT & & & 1 & 0 & & \\
\hline \multicolumn{7}{|l|}{ BTLA } \\
\hline rs 2971205 & Chr3 & 112184772 & & & $<0.01$ & 0.99 \\
\hline AA & & & 130 & 69 & & \\
\hline $\mathrm{AG}$ & & & 1 & 0 & & \\
\hline rs2171513 & Chr3 & 112184927 & & & 3.07 & 0.22 \\
\hline AA & & & 15 & 3 & & \\
\hline $\mathrm{AG}$ & & & 42 & 25 & & \\
\hline GG & & & 74 & 41 & & \\
\hline rs770019001 & Chr3 & 112184932 & & & $<0.01$ & 0.99 \\
\hline $\mathrm{CC}$ & & & 130 & 69 & & \\
\hline $\mathrm{CG}$ & & & 1 & 0 & & \\
\hline
\end{tabular}

(Continued) 


\begin{tabular}{|c|c|c|c|c|c|c|}
\hline \multirow{2}{*}{ Genotype } & \multirow{2}{*}{ Chromosome } & \multirow{2}{*}{ Position } & \multirow{2}{*}{$\begin{array}{l}\text { Stable group } \\
\quad(n=131)\end{array}$} & \multirow{2}{*}{$\begin{array}{c}\text { ABMR group } \\
(n=69)\end{array}$} & \multicolumn{2}{|c|}{ HWE for the stable group } \\
\hline & & & & & $\mathbf{X} 2$ & $P$ value \\
\hline rs9288952 & Chr3 & 112185025 & & & 3.87 & 0.14 \\
\hline GG & & & 24 & 5 & & \\
\hline GA & & & 48 & 29 & & \\
\hline $\mathrm{AA}$ & & & 59 & 35 & & \\
\hline rs 76844316 & Chr3 & 112188609 & & & 0.02 & 0.99 \\
\hline TT & & & 110 & 61 & & \\
\hline TG & & & 20 & 8 & & \\
\hline GG & & & 1 & 0 & & \\
\hline rs16859629 & Chr3 & 112190380 & & & $<0.01$ & 0.99 \\
\hline TT & & & 130 & 69 & & \\
\hline $\mathrm{TC}$ & & & 1 & 0 & & \\
\hline rs9851198 & Chr3 & 117448419 & & & $<0.01$ & 0.99 \\
\hline GG & & & 131 & 68 & & \\
\hline $\mathrm{AA}$ & & & 0 & 1 & & \\
\hline \multicolumn{7}{|l|}{ CD160 } \\
\hline rs2231375 & Chr1 & 145696694 & & & 0.67 & 0.71 \\
\hline GG & & & 96 & 55 & & \\
\hline GA & & & 31 & 13 & & \\
\hline AA & & & 4 & 1 & & \\
\hline rs 3766526 & Chr1 & 145698637 & & & $<0.01$ & 0.99 \\
\hline GG & & & 131 & 68 & & \\
\hline GA & & & 0 & 1 & & \\
\hline rs368476773 & Chr1 & 145698914 & & & $<0.01$ & 0.99 \\
\hline $\mathrm{CC}$ & & & 131 & 68 & & \\
\hline $\mathrm{CT}$ & & & 0 & 1 & & \\
\hline rs193141418 & Chr1 & 145698935 & & & 0.06 & 0.97 \\
\hline $\mathrm{CC}$ & & & 125 & 68 & & \\
\hline $\mathrm{CT}$ & & & 6 & 1 & & \\
\hline rs587741068 & Chr1 & 145703913 & & & $<0.01$ & 0.99 \\
\hline AA & & & 130 & 69 & & \\
\hline $\mathrm{AG}$ & & & 1 & 0 & & \\
\hline rs587727931 & Chr1 & 145704474 & & & $<0.01$ & 0.99 \\
\hline GG & & & 130 & 69 & & \\
\hline GA & & & 1 & 0 & & \\
\hline
\end{tabular}

Abbreviations: ABMR, antibody-mediated rejection; HVEM, herpes virus entry mediator; LIGHT, homologous to lymphotoxin (lymphotoxin-like), exhibits inducible expression and competes with HSV glycoprotein D for binding to herpesvirus entry mediator, a receptor expressed on T lymphocytes; BTLA, B and T lymphocyte attenuator; CD, cluster of differentiation; NA, not available; HWE, hardy-weinberg equilibrium. 
Table 3: Regression analysis for age-, sex- and immunosuppressive protocol-adjusted $B T L A / H V E M / C D 160 / L I G H T$ genetic polymorphisms among recipients with ABMR

\begin{tabular}{|c|c|c|c|c|}
\hline SNPs & model & OR & $95 \%$ CIs & $P$ value \\
\hline \multicolumn{5}{|c|}{ rs2971205 } \\
\hline & Additive & NA & NA & 1.00 \\
\hline & Dominant & NA & NA & 1.00 \\
\hline \multicolumn{5}{|c|}{ rs2171513 } \\
\hline & Additive & 0.81 & $0.51,1.29$ & 0.38 \\
\hline & Dominant & 0.92 & $0.50,1.69$ & 0.79 \\
\hline & Recessive & 0.36 & $0.10,1.33$ & 0.13 \\
\hline & HET & 1.11 & $0.59,2.11$ & 0.74 \\
\hline & HOM & 0.38 & $0.10,1.41$ & 0.15 \\
\hline \multicolumn{5}{|c|}{ rs770019001 } \\
\hline & Additive & NA & NA & 1.00 \\
\hline & Dominant & NA & NA & 1.00 \\
\hline \multicolumn{5}{|c|}{ rs9288952 } \\
\hline & Additive & 0.74 & $0.48,1.15$ & 0.18 \\
\hline & Dominant & 0.85 & $0.47,1.55$ & 0.60 \\
\hline & Recessive & 0.37 & $0.13,1.03$ & 0.06 \\
\hline & HET & 1.08 & $0.57,2.04$ & 0.82 \\
\hline & HOM & 0.38 & $0.13,1.11$ & 0.08 \\
\hline \multicolumn{5}{|c|}{ rs76844316 } \\
\hline & Additive & 0.72 & $0.30,1.70$ & 0.45 \\
\hline & Dominant & 0.74 & $0.30,1.81$ & 0.51 \\
\hline & Recessive & NA & NA & 1.00 \\
\hline & HET & 0.77 & $0.31,1.89$ & 0.57 \\
\hline & $\mathrm{HOM}$ & NA & NA & 1.00 \\
\hline \multicolumn{5}{|c|}{ rs16859629 } \\
\hline & Additive & NA & NA & 1.00 \\
\hline & Dominant & NA & NA & 1.00 \\
\hline \multicolumn{5}{|c|}{ rs9851198 } \\
\hline & Additive & NA & NA & 1.00 \\
\hline & Dominant & NA & NA & 1.00 \\
\hline \multicolumn{5}{|c|}{ rs4870 } \\
\hline & Additive & 0.83 & $0.53,1.28$ & 0.39 \\
\hline & Dominant & 0.77 & $0.41,1.45$ & 0.42 \\
\hline & Recessive & 0.80 & $0.36,1.78$ & 0.58 \\
\hline & HET & 0.80 & $0.41,1.56$ & 0.50 \\
\hline & HOM & 0.69 & $0.28,1.70$ & 0.42 \\
\hline
\end{tabular}




\begin{tabular}{|c|c|c|c|c|}
\hline SNPs & model & OR & $95 \%$ CIs & $P$ value \\
\hline \multicolumn{5}{|c|}{ rs2234158 } \\
\hline & Additive & NA & NA & 1.00 \\
\hline & Dominant & NA & NA & 1.00 \\
\hline \multicolumn{5}{|c|}{ rs376994775 } \\
\hline & Additive & NA & NA & 1.00 \\
\hline & Dominant & NA & NA & 1.00 \\
\hline \multicolumn{5}{|c|}{ rs754021885 } \\
\hline & Additive & 3.06 & $0.18,52.98$ & 0.44 \\
\hline & Dominant & 3.06 & $0.18,52.98$ & 0.44 \\
\hline \multicolumn{5}{|c|}{ rs572222644 } \\
\hline & Additive & NA & NA & 1.00 \\
\hline & Dominant & NA & NA & 1.00 \\
\hline \multicolumn{5}{|c|}{ rs2234161 } \\
\hline & Additive & 0.92 & $0.60,1.40$ & 0.68 \\
\hline & Dominant & 0.96 & $0.49,1.86$ & 0.90 \\
\hline & Recessive & 0.81 & $0.39,1.68$ & 0.58 \\
\hline & HET & 1.02 & $0.51,2.06$ & 0.95 \\
\hline & $\mathrm{HOM}$ & 0.82 & $0.35,1.94$ & 0.66 \\
\hline \multicolumn{5}{|c|}{ rs2234162 } \\
\hline & Additive & NA & NA & 1.00 \\
\hline & Dominant & NA & NA & 1.00 \\
\hline \multicolumn{5}{|c|}{ rs 2234163} \\
\hline & Additive & 1.83 & $0.66,5.04$ & 0.24 \\
\hline & Dominant & 1.66 & $0.54,5.11$ & 0.38 \\
\hline \multicolumn{5}{|c|}{ rs2234165 } \\
\hline & Additive & 1.01 & $0.35,2.91$ & 0.99 \\
\hline & Dominant & 1.01 & $0.35,2.91$ & 0.99 \\
\hline \multicolumn{5}{|c|}{ rs575127151 } \\
\hline & Additive & NA & NA & 1.00 \\
\hline & Dominant & NA & NA & 1.00 \\
\hline \multicolumn{5}{|c|}{ rs375010878 } \\
\hline & Additive & 2.39 & $0.14,40.69$ & 0.55 \\
\hline & Dominant & 2.39 & $0.14,40.69$ & 0.55 \\
\hline \multicolumn{5}{|c|}{ rs2234167 } \\
\hline & Additive & 0.80 & $0.20,3.17$ & 0.75 \\
\hline & Dominant & 0.80 & $0.20,3.17$ & 0.75 \\
\hline
\end{tabular}




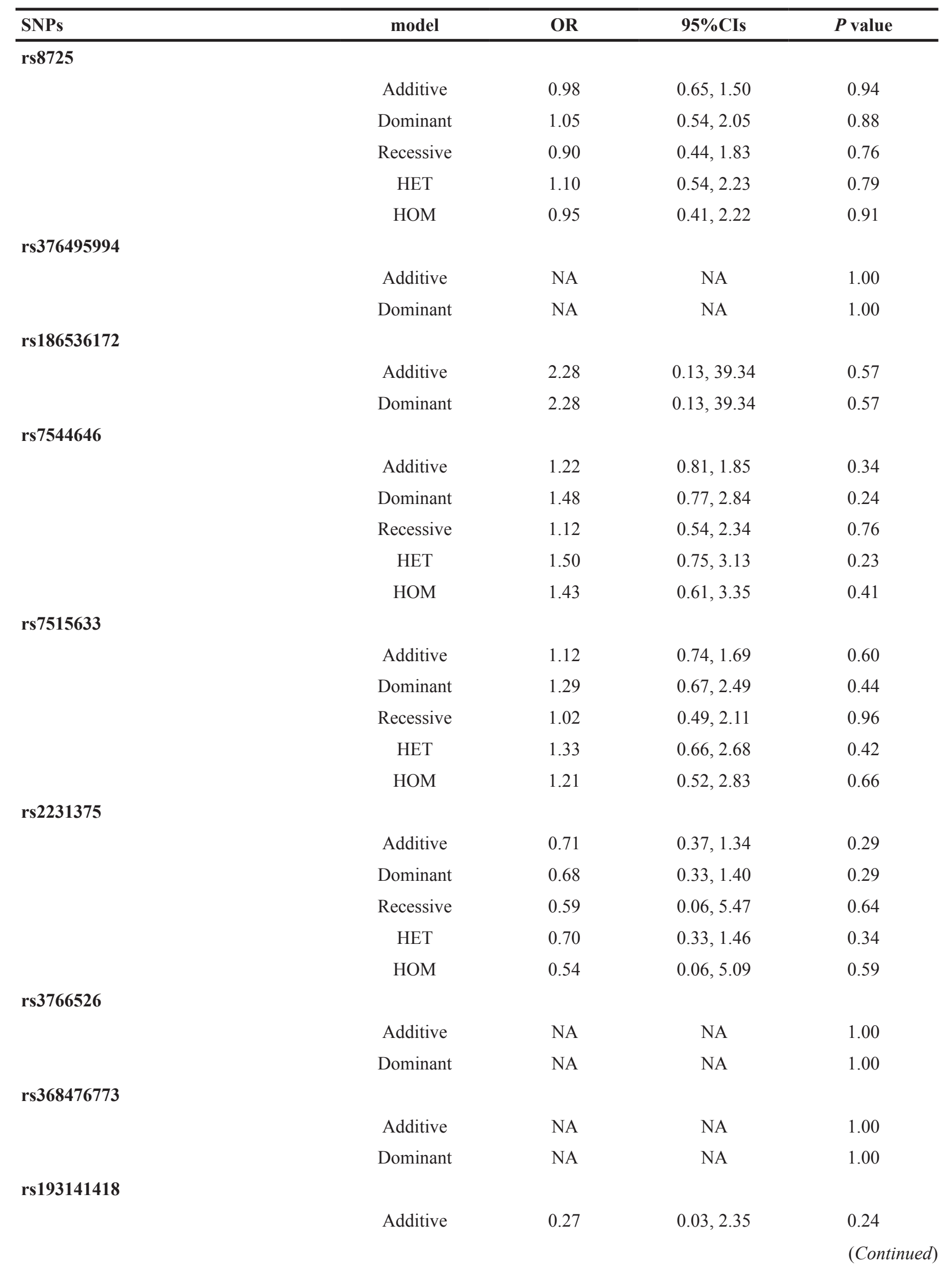




\begin{tabular}{|c|c|c|c|c|}
\hline SNPs & model & OR & $95 \%$ CIs & $P$ value \\
\hline & Dominant & 0.27 & $0.03,2.35$ & 0.24 \\
\hline \multicolumn{5}{|c|}{ rs587741068 } \\
\hline & Additive & NA & NA & 1.00 \\
\hline & Dominant & NA & NA & 1.00 \\
\hline \multicolumn{5}{|c|}{ rs587727931 } \\
\hline & Additive & NA & NA & 1.00 \\
\hline & Dominant & NA & NA & 1.00 \\
\hline \multicolumn{5}{|c|}{ rs344560 } \\
\hline & Additive & 1.01 & $0.38,2.69$ & 0.99 \\
\hline & Dominant & 1.01 & $0.38,2.69$ & 0.99 \\
\hline \multicolumn{5}{|c|}{ rs772372888 } \\
\hline & Additive & NA & NA & 1.00 \\
\hline & Dominant & NA & NA & 1.00 \\
\hline \multicolumn{5}{|c|}{ rs61761328 } \\
\hline & Additive & NA & NA & 1.00 \\
\hline & Dominant & NA & NA & 1.00 \\
\hline \multicolumn{5}{|c|}{ rs183886666 } \\
\hline & Additive & NA & NA & 1.00 \\
\hline & Dominant & NA & NA & 1.00 \\
\hline \multicolumn{5}{|c|}{ rs8101047 } \\
\hline & Additive & 1.02 & $0.58,1.81$ & 0.94 \\
\hline & Dominant & 1.18 & $0.63,2.21$ & 0.60 \\
\hline & Recessive & NA & NA & 1.00 \\
\hline & HET & 1.31 & $0.70,2.47$ & 0.40 \\
\hline & HOM & NA & NA & 1.00 \\
\hline \multicolumn{5}{|c|}{ rs542346038 } \\
\hline & Additive & NA & NA & 1.00 \\
\hline & Dominant & NA & NA & 1.00 \\
\hline \multicolumn{5}{|c|}{ rs2291668 } \\
\hline & Additive & 1.20 & $0.74,1.94$ & 0.46 \\
\hline & Dominant & 1.51 & $0.82,2.79$ & 0.18 \\
\hline & Recessive & 0.66 & $0.21,2.07$ & 0.48 \\
\hline & HET & 1.65 & $0.88,3.08$ & 0.12 \\
\hline & $\mathrm{HOM}$ & 0.87 & $0.26,2.88$ & 0.82 \\
\hline \multicolumn{5}{|c|}{ rs2291667 } \\
\hline & Additive & 2.32 & $0.43,12.64$ & 0.33 \\
\hline & Dominant & 2.32 & $0.43,12.64$ & 0.33 \\
\hline
\end{tabular}




\begin{tabular}{lcccc}
\hline SNPs & model & OR & $\mathbf{9 5 \% C I s}$ & $\boldsymbol{P}$ value \\
\hline rs748673655 & & & & \\
& Additive & NA & NA & 1.00 \\
rs344558 & Dominant & NA & NA & 1.00 \\
& & & \\
& Additive & 1.77 & $0.80,3.95$ & 0.16 \\
& Dominant & 1.67 & $0.72,3.89$ & 0.23 \\
rs563748272 & Recessive & NA & NA & 1.00 \\
& HET & 1.53 & $0.65,3.62$ & 0.33 \\
& HOM & NA & NA & 1.00 \\
& & & NA & 1.00 \\
\hline
\end{tabular}

Abbreviations: SNPs, single nuclear polymorphisms; OR, odds ratio; CIs: confidential intervals.

did not find any significant association between 17 SNPs of HVEM and the onset of ABMR in renal transplant recipients.

LIGHT, a member of the TNF cytokine superfamily, is a type II transmembrane glycoprotein that is widely expressed on hematopoietic cells at certain periods of cell differentiation, including $\mathrm{T}$ cells, B cells, DC, NK cells and platelets, acting as a key cytokine with multiple functions [13, 23]. LIGHT-deficient mice survived slightly longer than control mice (10 days versus 7 days) in fully MHC-mismatched cardiac transplantation, implying that the HVEM/LIGHT pathway has potential functions in transplantation [24]. Meanwhile, in the humoral immune response, recent work suggests that LIGHT participates in B cell expansion and promotes Ig production [17]. LIGHT binds to three receptors: HVEM, LT $\beta R$ and DcR3. The human LIGHT gene is situated on a segment of chromosome 19p13.3, which is paralogous to the MHC immune response loci [23]. Previous investigations have demonstrated that rs344560, located near the receptor-binding region of LIGHT, directly influences the binding avidity to LT $\beta R$, whereas rs2291667, positioned in the cytosolic domain, which could decrease the binding avidity to DcR3 and lowers the expression of LIGHT on the cell membrane [25]. Heterotrimers of SNPs are associated with lower DcR3 avidity and the increased LIGHT bioavailability, contributing to the pathogenesis of inflammatory diseases, such as rheumatoid arthritis. However, in our study, we did not find any significant differences in SNP distributions on LIGHT genes between the ABMR and control group of renal transplant recipients, calling for a deeper investigation into the functions of $L I G H T$ in ABMR.

The BTLA gene is located on chromosome 3 in q13.2 with five exons [26]. BTLA is a member of the immunoglobulin superfamily and is constitutively expressed on naïve T and B cells, NK cells, macrophages and dendritic cells at low levels [10]. BTLA is up-regulated on activated T cells, but when conjugated with HVEM, a co-inhibitory signal suppresses $\mathrm{T}$ cell activation and differentiation in vitro [12]. Studies regarding the genetic variations of $B T L A$ have mainly focused on its role in cancer (for example, lymphocytic leukemia [27] and breast cancer [28]) and susceptibility to autoimmune diseases (for example, rheumatoid arthritis [29, 30], systemic lupus erythematosus and type 1 diabetes mellitus [31]). In particular, the majority of investigation have focused on rs9288952 and its role in increasing breast cancer risk in Chinese populations [28] and rheumatoid arthritis in Japanese and Taiwanese populations $[30,31]$. Inuo et al. revealed no relationship between rs2171513 and susceptibility to lupus erythematosus and type 1 diabetes mellitus in Japanese populations [31]. While, Oki et al. showed rs76844316 is significantly related to rheumatoid arthritis in Japanese populations [29]. Our study is the first to investigate the association between BTLA SNPs with the development of ABMR in renal transplant recipients. None of the seven BTLA SNPs we screened, including the three SNPs mentioned above, showed any association with ABMR.

CD160 is another member of the Ig superfamily and is glycosylphosphatidylinositol anchored on the cell membrane [32]. It is also the second co-inhibitory ligand of HVEM, commonly associated with cytolytic activity in NK, NKT, and CD8+ T cells [33]. A recent study suggests that CD160 signaling is vital in activating CD28independent effector/memory CD8+ alloreactive T cells. This is because CD160Ig inhibits alloreactive CD8+ T cell proliferation and IFN- $\gamma$ production in vitro, particularly in the absence of CD28 costimulation, resulting in the prolonged survival of fully mismatched cardiac allograft in CD4-/-, CD28-/- knockout and CTLA4Ig treated wild type recipients [34]. However, there are no studies 
available that address the association between CD160 and humoral immunity, including polymorphism of CD160 and the onset of allograft rejection. In our study, none of the six CD160 SNPs showed any significant association with the occurrence of ABMR in renal transplant recipients.

This study is a first attempt in addressing the functions of $H V E M / L I G H T / B T L A / C D 160$ cosignaling pathway in the pathogenesis of ABMR in renal transplant patients. While our results suggest that the $41 \mathrm{HVEM} /$ $L I G H T / B T L A / C D 160$ SNPs that we screened are not associated with the onset of ABMR, there are several advantages in our approach. First, we collected sufficient baseline information about the patients and included an adequate number of control patients. Second, we adopted NGS technology, which allows high-throughput and largescale analysis of the genotypes, increasing the reliability of our findings. Third, we used regression analysis after adjusting the data for multiple confounding factors to obtain more detailed clinical information. Moreover, considering various causing contribute to the pathogenesis of post-transplant ABMR, we failed to collect more ABMR-related information to analysis the distributions of these causing and its relationship with SNPs in our study. Therefore, further studies are required with larger sample sizes from different populations to fully understand the role of these genes in ABMR onset.

In summary, through a case-control study on 69 renal transplant recipients with $\mathrm{ABMR}$ and 131 control recipients, we provide the first study to explore the association between HVEM/LIGHT/BTLA/CD160 gene polymorphisms and $\mathrm{ABMR}$ in renal transplant recipients. We showed that none of the 41 HVEM/LIGHT/BTLA/ $C D 160$ gene polymorphisms were associated with ABMR. Since there are limited studies investigating the role of the costimulatory signaling pathways in graft rejection, we recommend further research is required to gain a deeper understanding of the role of these genes and its variants in ABMR after kidney transplantation.

\section{MATERIALS AND METHODS}

\section{Ethics statement}

The procedures followed in our study were in accordance with the ethical standards of the Declarations of Helsinki and Istanbul. The study was limited to the living-related transplantation of kidney tissues to lineal or collateral relatives not beyond the third degree of kinship, or transplantation of kidney tissues from cadaveric allograft donors after cardiac death. The protocols followed were approved by the local ethics committee of The First Affiliated Hospital with Nanjing Medical University. We obtained written informed consent from all transplant recipients. None of the transplant donors were considered vulnerable.

\section{Collection of patient data}

The study included 200 renal transplant recipients who underwent kidney transplantation between February 2008 and December 2015 at the Kidney Transplant Center of The First Affiliated Hospital of Nanjing Medical University. At least two clinicians critically reviewed the transplant recipients' medical records, and extracted relevant data, including age, gender, transplant date, duration of transplantation, number of transplants, and immunosuppressive protocol, for patient selection. They also extracted data on panel reactive antibodies and HLA mismatch during the pre-transplant period.

Methylprednisolone was intravenously administered at a dosage of $500 \mathrm{mg}$ /day during surgery and for two days following the procedure. Following this, the dosage was reduced to $400 \mathrm{mg}, 300 \mathrm{mg}, 200 \mathrm{mg}$, and then 80 $\mathrm{mg}$ on each subsequent day. This was followed by administration of prednisone at a dosage of $30 \mathrm{mg} /$ day as maintenance therapy. In addition, basiliximab (20 mg) was intravenously administered $30 \mathrm{~min}$ before the procedure and on the fourth day after the procedure. All recipients received a three-drug or four-drug immunosuppressive regimen: cyclosporin A $(n=101)$ or tacrolimus $(n=99)$ combined with mycophenolate mofetil and prednisone, with or without sirolimus $(\mathrm{n}=17)$. The starting dose of cyclosporine A and tacrolimus was $8 \mathrm{mg} \cdot \mathrm{kg}^{-1} \cdot \mathrm{day}^{-1}$ and $0.2 \mathrm{mg} \cdot \mathrm{kg}^{-1} \cdot \mathrm{day}^{-1}$, respectively; these doses were later adjusted according to serum creatinine levels. In patients where ABMR episodes occurred, methylprednisolone was intravenously administered at a dosage of $200 \mathrm{mg} /$ day for three to five days.

\section{Diagnosis of antibody-mediated rejection}

We considered an increase in serum creatinine by $20 \%$ from the baseline (not attributable to other causes), fever, proteinuria and pain in the region of the transplanted kidney to be indicative of ABMR. To confirm the diagnosis, we analyzed allograft biopsies according to the Banff 07 classification criteria, which included positive C4d staining, presence of circulating DSAs and morphological evidence of acute tissue injury [35]. Moreover, patients diagnosed with either acute ABMR or chronic active ABMR were all included in our study.

\section{Sample collection, preparation and NGS}

We collected peripheral blood samples $(2 \mathrm{~mL})$ from each recipient and extracted DNA using the QIAmp DNA mini kit (Qiagen, Hilden, Germany). We quantitatively analyzed the concentration and purity of genomic DNA (gDNA) using NanoDrop ND2000 (Thermo, MA, USA), and assessed gene integrity using agarose gel electrophoresis. We considered gDNA samples with a total mass of $\geq 1 \mu \mathrm{g}$ and A260/A280 absorbance ratio of 
$\geq 1.80$ and $\leq 2.0$ as acceptable. Then, we selected a pool containing upstream and downstream oligonucleotides specific to the target regions of interest as gDNA hybrids. We next fragmented gDNA using a Bioruptor Interrupt instrument (Diagenode, Belgium), and performed quantitative detection to ensure that the average fragment size was $150-250 \mathrm{bp}$. We then performed end repair, dAtailing and sequencing adaptor ligation using the $\mathrm{ABI}$ 9700 PCR instrument (ABI, USA). We amplified the adapter-ligated DNA by selective, limited-cycle PCR for five cycles, before quantitatively analyzing using the Qubit dsDNA HS Assay Kit (Invitrogen, USA). We hybridized the prepared library (750 ng) with $11 \mu \mathrm{L}$ of hybridization blocking buffer (Allwegene, China), $20 \mu \mathrm{L}$ of hybridization buffer (Allwegene, China) and a mixture of $5 \mu \mathrm{L}$ RNase block (Invitrogen, USA) and $2 \mu \mathrm{L}$ probes (Allwegene, China) overnight (at least $8-16 \mathrm{~h}$ ) at $65^{\circ} \mathrm{C}$. We mixed the hybridized products with $200 \mu \mathrm{L}$ Dynabeads MyOne Streptavidin T1 magnetic beads (Invitrogen, USA) for $30 \mathrm{~min}$ at room temperature. The products were then washed twice with a wash buffer (Allwegene, China), before the mixture was amplified for 16 PCR cycles and quantitatively assessed using the Qubit dsDNA HS Assay Kit (Invitrogen, USA). We denatured the captured libraries and loaded them onto an Illumina cBot instrument at a concentration of 12 to $16 \mathrm{pmol} / \mathrm{L}$ for cluster generation, according to the manufacturer's instructions. We sequenced up to 20 WUCaMP libraries per HiSeq lane. A PhiX control (Illumina) was added to lane 8 of each flow cell.

\section{Analysis of NGS data}

We analyzed sequencing data, including the number of altered chromosomes, genomic alterations and the depth of the sequencing coverage. We based all analyses on the human reference sequence UCSC hg19 assembly (NCBI build 37.2) using the Burrows-Wheeler Aligner. We performed local alignment and duplication removal using the Genome Analysis Tool Kit and Picard software. We detected SNPs using dbSNP 132. We used Gemini software to detect damaging or deleterious SNPs and prediction tools such as Sorting Intolerant from Tolerant and Polymorphism Phenotyping to analyze all human non-synonymous SNPs. In addition, we detected putative somatic variant calls with two separate programs: MuTect 1.1.5 and VarScan 2.3.6, by pairing each sample with its matched blood sample.

\section{Statistical analysis}

We determined conformance to the HWE using genotype frequencies obtained from a single gene. We used the chi-square test to compare the observed and expected values. We performed genotype association analysis using a dominant model (minor allele homozygotes plus heterozygotes vs. major allele homozygotes), recessive model (minor allele homozygotes vs. heterozygotes plus major homozygotes), additive model (major homozygotes vs. heterozygotes vs. minor homozygotes), HET model (major homozygotes vs. heterozygotes) and HOM model (major homozygotes vs. minor homozygotes). We compared genotypic frequencies between the control and ABMR group using the chi-square test. In addition, we explored linkage disequilibrium blocks using Haploview version 4.2. We calculated odds ratios (ORs) and 95\% confidence intervals (95\% CIs) using the SPSS 13.0 software (SPSS Inc., Chicago, IL, USA). We considered $P<0.05$ to indicate statistical significance. The OR provides an effect estimate: a value of less than one assumes a protective effect, while a value of more than one assumes an increased disease risk. In addition, we analyzed the genotypic distributions of $\mathrm{C} 4$ SNPs in recipients with ABMR and stable recipients using logistic regression models adjusted for age, sex and immunosuppressive protocol.

\section{Abbreviations}

ABMR: antibody-mediated rejection; HLA: human leukocyte antigens; MHC: major histocompatibility complex; DSA: donor-specific antibodies; HVEM: herpes virus entry mediator; BTLA: B and T lymphocyte attenuator; LIGHT: homologous to lymphotoxin, which exhibit inducible expression and compete with HSV glycoprotein D for binding to HVEM, a receptor expressed on T lymphocytes); GC: germinal center; DC: dendritic cells; Tfh: helper cells; SNP: single nucleotide polymorphisms; HWE: Hardy-Weinberg equilibrium; NGS: next-generation sequencing; CRD: cysteine-rich domain.

\section{Author contributions}

Zijie Wang: sample collection, statistical analysis and manuscript preparation;

Ke Wang: sample collection and manuscript preparation;

Haiwei Yang: gene testing and study design;

Zhijian Han: statistical analysis;

Jun Tao: statistical analysis;

Hao Chen: sample collection;

Yuqiu Ge: statistical analysis;

Miao Guo: statistical analysis and gene testing;

Chuanjian Suo: sample collection;

Ruoyun Tan: funding and study design;

Ji-Fu Wei: study design, gene testing and manuscript preparation;

Min Gu: study design, funding and manuscript preparation. 


\section{CONFLICTS OF INTERESTS}

The authors have declared that no competing interests exist.

\section{FUNDING}

This work was supported by the National Natural Science Foundation of China [grant numbers 81570676, 81100532, 81470981], the Science and Education Health Project of Jiangsu Province for Important Talent [grant number RC2011055], the "333 High Level Talents Project" in Jiangsu Province, China [grant numbers BRA2015469, BRA2016514 (2011 and 2013)], the Standardized Diagnosis and Treatment Research Program of Key Diseases in Jiangsu Province, China [grant number BE2016791], the Open Project Program of Health Department of Jiangsu Province, China [grant number JSY-2-2016-099], the Jiangsu Province Six Talents Peak from Department of Human Resources, Social Security Office of Jiangsu Province, China [grant numbers 2010WSN-56, 2011-WS-033], the General Program of Health Department of Jiangsu Province, China [grant number H2009907], and the Priority Academic Program Development of Jiangsu Higher Education Institutions [grant number JX10231801]. National Key R\&D Plan for Precision Medicine [grant number 2017YFC0910001].

\section{REFERENCES}

1. Tonelli M, Wiebe N, Knoll G, Bello A, Browne S, Jadhav D, Klarenbach S, Gill J. Systematic review: kidney transplantation compared with dialysis in clinically relevant outcomes. Am J Transplant. 2011;11; 2093-2109. https:// doi.org/10.1111/j.1600-6143.2011.03686.x.

2. Garces JC, Giusti S, Staffeld-Coit C, Bohorquez H, Cohen AJ, Loss GE. Antibody-Mediated Rejection: A Review. Ochsner. J 2017;17; 46-55.

3. Kim M, Martin ST, Townsend KR, Gabardi S. Antibodymediated rejection in kidney transplantation: a review of pathophysiology, diagnosis, and treatment options. Pharmacotherapy. 2014;34: 733-744. https://doi. org/10.1002/phar.1426.

4. Halloran PF. The clinical importance of alloantibodymediated rejection. Am J Transplant. 2003;3: 639-640.

5. Davis S, Cooper JE. Acute antibody-mediated rejection in kidney transplant recipients. Transplantation reviews. 2017;31: 47-54. https://doi.org/10.1016/j.trre.2016.10.004.

6. Sigdel TK, Sarwal MM. Moving beyond HLA: a review of nHLA antibodies in organ transplantation. Human immunology. 2013;74: 1486-1490. https://doi.org/10.1016/j. humimm.2013.07.001.

7. Colvin RB, Smith RN. Antibody-mediated organ-allograft rejection. Nature reviews. Immunology. 2005;5: 807817. https://doi.org/10.1038/nri1702.
8. Chehade H, Pascual M. The Challenge of Acute Antibody-Mediated Rejection in Kidney Transplantation. Transplantation. 2016;100: 264-265. https://doi. org/10.1097/tp.0000000000000959.

9. Li XC, Rothstein DM, Sayegh MH. Costimulatory pathways in transplantation: challenges and new developments. Immunol Rev. 2009;229: 271-293. https:// doi.org/10.1111/j.1600-065X.2009.00781.x.

10. Pilat N, Sayegh MH, Wekerle T. Costimulatory pathways in transplantation. Semin Immunol. 2011;23: 293-303. https:// doi.org/10.1016/j.smim.2011.04.002.

11. Adams AB, Larsen CP, Pearson TC, Newell KA. The role of TNF receptor and TNF superfamily molecules in organ transplantation. American journal of transplantation. 2002;2: 12-18.

12. Watanabe N, Gavrieli M, Sedy JR, Yang J, Fallarino F, Loftin SK, Hurchla MA, Zimmerman N, Sim J, Zang X, Murphy TL, Russell JH, Allison JP. BTLA is a lymphocyte inhibitory receptor with similarities to CTLA-4 and PD-1. Nature immunology. 2003;4: 670-679. https://doi. org/10.1038/ni944.

13. del Rio ML, Lucas CL, Buhler L, Rayat G, RodriguezBarbosa JI. HVEM/LIGHT/BTLA/CD160 cosignaling pathways as targets for immune regulation. Journal of leukocyte biology. 2010;87: 223-235. https://doi. org/10.1189/jlb.0809590.

14. Tamada K, Shimozaki K, Chapoval AI, Zhai Y, Su J, Chen SF, Hsieh SL, Nagata S, Ni J, Chen L. LIGHT, a TNF-like molecule, costimulates $\mathrm{T}$ cell proliferation and is required for dendritic cell-mediated allogeneic $\mathrm{T}$ cell response. $\mathrm{J}$ Immunol. 2000;164: 4105-4110.

15. Steinberg MW, Cheung TC, Ware CF. The signaling networks of the herpesvirus entry mediator (TNFRSF14) in immune regulation. Immunological reviews. 2011;244: 169187. https://doi.org/10.1111/j.1600-065X.2011.01064.x.

16. del Rio ML, Buhler L, Gibbons C, Tian J, RodriguezBarbosa JI. PD-1/PD-L1, PD-1/PD-L2, and other co-inhibitory signaling pathways in transplantation. Transpl Int. 2008;21: 1015-1028. https://doi. org/10.1111/j.1432-2277.2008.00726.x.

17. Duhen T, Pasero C, Mallet F, Barbarat B, Olive D, Costello RT. LIGHT costimulates CD40 triggering and induces immunoglobulin secretion; a novel key partner in T celldependent B cell terminal differentiation. European journal of immunology. 2004;34: 3534-3541. https://doi. org/10.1002/eji.200425598.

18. Conlon TM, Saeb-Parsy K, Cole JL, Motallebzadeh R, Qureshi MS, Rehakova S, Negus MC, Callaghan CJ, Bolton EM, Bradley JA, Pettigrew GJ. Germinal center alloantibody responses are mediated exclusively by indirect-pathway CD4 T follicular helper cells. J Immunol. 2012;188: 26432652. https://doi.org/10.4049/jimmunol.1102830.

19. Steele DJ, Laufer TM, Smiley ST, Ando Y, Grusby MJ, Glimcher LH, Auchincloss H Jr. Two levels of help for B 
cell alloantibody production. The Journal of experimental medicine. 1996;183: 699-703.

20. de Graav GN, Dieterich M, Hesselink DA, Boer K, Clahsenvan Groningen MC, Kraaijeveld R, Litjens NH, Bouamar R, Vanderlocht J, Tilanus M, Houba I, Boonstra A, Roelen DL, et al. Follicular T helper cells and humoral reactivity in kidney transplant patients. Clinical and experimental immunology. 2015;180: 329-340. https://doi.org/10.1111/ cei. 12576 .

21. McGrath MM, Najafian N. The role of coinhibitory signaling pathways in transplantation and tolerance. Frontiers in immunology. 2012;3: 47. https://doi. org/10.3389/fimmu.2012.00047.

22. Li D, Fu Z, Chen S, Yuan W, Liu Y, Li L, Pang D, Li D. HVEM gene polymorphisms are associated with sporadic breast cancer in Chinese women. PloS one. 2013;8: e71040. https://doi.org/10.1371/journal.pone.0071040.

23. Granger SW, Butrovich KD, Houshmand P, Edwards WR, Ware CF. Genomic characterization of LIGHT reveals linkage to an immune response locus on chromosome $19 \mathrm{p} 13.3$ and distinct isoforms generated by alternate splicing or proteolysis. J Immunol. 2001;167: 5122-5128.

24. Ye Q, Fraser CC, Gao W, Wang L, Busfield SJ, Wang C, Qiu Y, Coyle AJ, Gutierrez-Ramos JC, Hancock WW. Modulation of LIGHT-HVEM costimulation prolongs cardiac allograft survival. The Journal of experimental medicine. 2002;195: 795-800.

25. Cheung TC, Coppieters K, Sanjo H, Oborne LM, Norris PS, Coddington A, Granger SW, Elewaut D, Ware CF. Polymorphic variants of LIGHT (TNF superfamily-14) alter receptor avidity and bioavailability. J Immunol. 2010;185: 1949-1958. https://doi.org/10.4049/jimmunol.1001159.

26. Partyka A, Woszczyk D, Strzała T, Szczepańska A, Tomkiewicz A, Frydecka I, Karabon L. Gene polymorphisms of novel immunotolerant molecule BTLA: distribution of alleles, genotypes and haplotypes in Polish Caucasian population. Arch Immunol Ther Exp (Warsz). 2015;63: 73-78. https://doi.org/10.1007/ s00005-014-0300-3.

27. Karabon L, Partyka A, Jasek M, Lech-Maranda E, Grzybowska-Izydorczyk O, Bojarska-Junak A, PawlakAdamska E, Tomkiewicz A, Robak T, Rolinski J, Frydecka I. Intragenic Variations in BTLA Gene Influence mRNA Expression of BTLA Gene in Chronic Lymphocytic Leukemia Patients and Confer Susceptibility to Chronic
Lymphocytic Leukemia. Arch Immunol Ther Exp (Warsz). 2016;64: 137-145. https://doi.org/10.1007/ s00005-016-0430-x.

28. Fu Z, Li D, Jiang W, Wang L, Zhang J, Xu F, Pang D, Li D. Association of BTLA gene polymorphisms with the risk of malignant breast cancer in Chinese women of Heilongjiang Province. Breast Cancer Res Treat. 2010;120: 195-202. https://doi.org/10.1007/s10549-009-0462-6.

29. Oki M, Watanabe N, Owada T, Oya Y, Ikeda K, Saito Y, Matsumura R, Seto Y, Iwamoto I, Nakajima H. A functional polymorphism in $\mathrm{B}$ and $\mathrm{T}$ lymphocyte attenuator is associated with susceptibility to rheumatoid arthritis. Clinical \& developmental immunology. 2011;2011: 305656. https://doi.org/10.1155/2011/305656.

30. Lin SC, Kuo CC, Chan CH. Association of a BTLA gene polymorphism with the risk of rheumatoid arthritis. Journal of biomedical science. 2006;13: 853-860. https://doi. org/10.1007/s11373-006-9113-7.

31. Inuo M, Ihara K, Matsuo T, Kohno H, Hara T. Association study between B- and T-lymphocyte attenuator gene and type 1 diabetes mellitus or systemic lupus erythematosus in the Japanese population. International journal of immunogenetics. 2009;36: 65-68. https://doi. org/10.1111/j.1744-313X.2008.00809.x.

32. Maïza H, Leca G, Mansur IG, Schiavon V, Boumsell L, Bensussan A. A novel $80-\mathrm{kD}$ cell surface structure identifies human circulating lymphocytes with natural killer activity. The Journal of experimental medicine. 1993;178: $1121-1126$

33. Krummey SM, Ford ML. New insights into T-cell cosignaling in allograft rejection and survival. Current opinion in organ transplantation. 2015;20: 43-48. https:// doi.org/10.1097/mot.0000000000000151.

34. D'Addio F, Ueno T, Clarkson M, Zhu B, Vergani A, Freeman GJ, Sayegh MH, Ansari MJ, Fiorina P, Habicht A. CD160Ig fusion protein targets a novel costimulatory pathway and prolongs allograft survival. PloS one. 2013;8: e60391. https://doi.org/10.1371/journal.pone.0060391.

35. Solez K, Colvin RB, Racusen LC, Haas M, Sis B, Mengel M, Halloran PF, Baldwin W, Banfi G, Collins AB, Cosio F, David DS, Drachenberg C, et al. Banff 07 classification of renal allograft pathology: updates and future directions. American journal of transplantation. 2008;8: 753760. https://doi.org/10.1111/j.1600-6143.2008.02159.x. 